
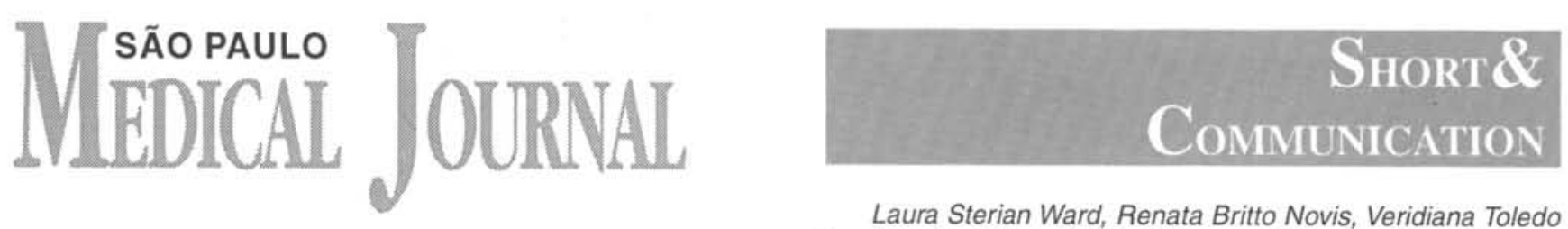

Laura Sterian Ward, Renata Britto Novis, Veridiana Toledo Nascimento, Miriam Siesler Nóbrega, Mário José Abdalla Saad

\title{
Determination of glucose levels using dried filter paper blood spots: new perspective in home monitoring
}

\author{
Department of Internal Medicine, Faculdade de Medicina, University of Campinas - Campinas, Brazil
}

\begin{abstract}
We present a method for the determination of blood glucose using dried filter paper blood spots. To validate this method, we compared our results using filter paper and simultaneously collected venous blood. We demonstrated that there is a linear relationship between the filter paper glucose levels and those determined in whole blood $(r=0.98)$. There was no significant difference between the results of the two methods $(p>0.05)$. This method is a cheap alternative which may improve the control of diabetes mellitus, and may also be very useful in the diagnosis of postprandial hypoglycemia and other special situations.
\end{abstract}

UNITERMS: Diabetes mellitus. Glycemic control. Blood glucose self-monitoring.

\section{INTRODUCTION}

$\mathrm{T}$ he results of the DCCT (Diabetes Control and Complications Trial), a large multicenter prospective trial designed to examine the effect of metabolic control on the development of diabetic complications, recently provided convincing evidence that glycemic control ameliorates such complications ${ }^{4}$.

Assessment of the blood glucose levels during the patient's daily activities outside the hospital may be an important aid in diabetes management ${ }^{5.14 .15}$. Several methods have been introduced for this purpose, including urine glucose measurements, glucose oxidase reagent strips and reflectance meters. It is well known that urine glucose measurements are no longer satisfactory as the only means of control outside the hospital ${ }^{11 .}{ }^{15}$. Therefore, therapeutic decisions depend on, among other things, the reliability of the blood glucose determinations ${ }^{5}$. When glucose concentrations are determined outside of the laboratory using tests strips and reflectomers, one must ensure perfect quality of the strips, reliable operation of the reflectomer and reproducible analitycal handling of the system ${ }^{16}$. In this regard, the socio-cultural and economic status of our patients are severe handicaps to home monitoring.

Glucose measurement using dried capillary blood spots on filter paper is an alternative means of home monitoring. This principle has previously been described ${ }^{6.17}$. The method is simple and cheap for the patient to use, requires little equipment, and is suitable for intermittent assessment of diurnal blood glucose curves or the temporary assessment of particular problems. The standardization of such a method for blood glucose determination could, therefore, provide a new perspective in diabetes management.

The purpose of this study was to describe and evaluate a reliable and reproducible technique for blood glucose quantification which could be employed in various situations outside the hospital.

\section{Address for correspondence:}

Mário José Abdalla Saad

Department of Internal Medicine FCM - UNICAMP

P. O. Box 1170

Campinas/SP - Brasil - CEP 13081-970

\section{MATERIAL AND METHODS}

Patients: We studied a total of 54 blood samples. Fortytwo of these were from normal subjects, eight were from 
persons with uncontrolled diabetes, and four were collected during an insulin tolerance test (ITT) after 15 minutes of insulin infusion.

Paper: We utilized a specially-printed filter paper from FITEC Ind. \& Com. de Filtro Ltda. This paper is 100 percent cotton. Each filter contained five numbered zones, each 2 $\mathrm{cm}$ in diameter (Fig. 1). All zones were identified and dated by writing directly on the filter paper.

Blood sampling: All subjects were asked to collect a drop of blood after pricking the lateral side of a finger tip with a common disposable needle and were instructed to put enough blood on the filter paper to fill at least one of the five circles completely. Following application of the specimen, the spot was examined to make sure that its size was approximately the same on both sides of the paper. The spotted papers were stored in an envelope at room temperature, where they were allowed to dry. We simultaneously collected $3 \mathrm{ml}$ of venous blood from all patients into tubes containing 2 percent sodium fluoride and calcium oxalate.

In order to improve the reproducibility, we soaked some of the filter papers in a 2 percent sodium fluoride solution prior to use; these papers were then air-dried at room temperature. To check the reproductive ability of the method, we calculated the coefficient variation of the absorbance values of all the standard points and samples from both sodium fluoride-treated and non-treated papers, using single and duplicate spots. The assays were repeated daily for eight days and thereafter some samples were analyzed at set intervals for up to four weeks.

Preparation for analysis: The centers of the blood spots were sampled with a handheld punch $5 \mathrm{~mm}$ in diameter. The blood content of such discs corresponded to about $10 \mathrm{ul}$

9/14 6:00 a.m.
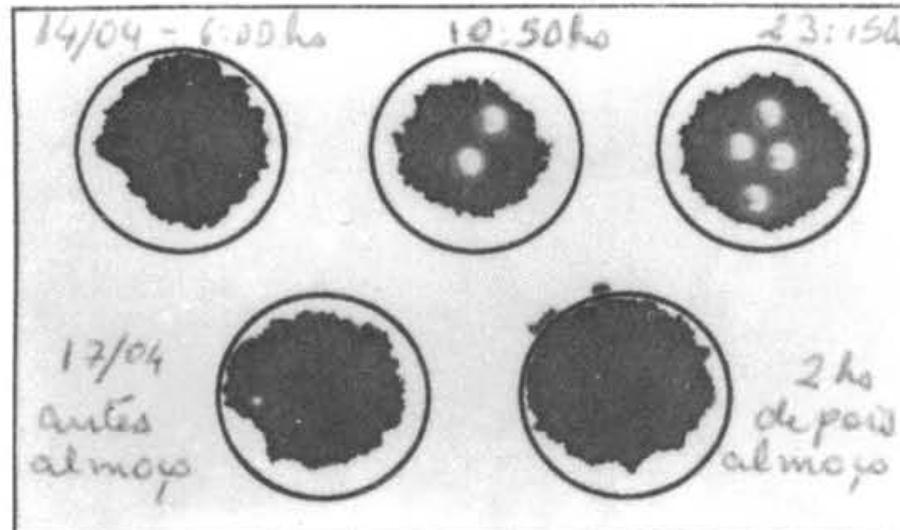

$4 / 17$

"Before lunch"

11:15 p.m.

Figure 1 - Filter paper with patient's personal notes. of blood. The discs were transferred to labeled test tubes containing $300 \mathrm{ul}$ of a 5 percent trichloroacetic acid solution and were eluted by shaking at 10-minute intervals for one hour at room temperature. The samples were then centrifuged at $3000 \mathrm{rpm}$ for 10 minutes.

As positive controls, $100 \mathrm{ul}$ samples of whole blood were prepared in an identical manner. The supernatants of the samples from blood spots, from whole blood and from the standards, were transferred to sampling tubes and immediately analysed under identical conditions, by the same method described herein ${ }^{10}$.

Standard curve preparation: $6 \mathrm{ml}$ of EDTA-treated venous blood were stored at room temperature for 24 hours to reach near zero glucose concentration (less than $2 \mathrm{mg}$ / $\mathrm{dL}$ ). One milliliter of the blood was then transfered to sodium fluoride -containing tubes and glucose was added to obtain final concentrations of 50, 100, 200 and $400 \mathrm{mg} / \mathrm{dl}$. Samples from each of these tubes were then spotted onto filter paper to then be eluted and processed as previously described.

Statistical analysis: Differences between groups were compared by one-way analysis of variance. Pearson's regression analysis was used when appropriate. $\mathrm{P}$ values $<0.005$ were considered to indicate statistical significance.

\section{RESULTS}

Since we collected blood from patients under very different conditions, we obtained a wide range of blood glucose values $(20-450 \mathrm{mg} / \mathrm{dl})$. This wasimportant to validate the method in conditions of hypo- and hyperglycemia.

The filter paper blood glucose levels were compared with those obtained using the routine method for venous blood glucose determinations. The results are shown in Figure 2. There was a linear relationship between the filter paper glucose values and those determined in whole blood $(r=0.98)$. There was no significant difference between the results of the two methods ( $p>0.05)$.

The standard curve was linear. The intraassay and interassay coefficient variations were both 6 percent. Figure 3 shows that the glucose concentration in the filter paper blood samples in the absence of glycolysis inhibitors was stable under laboratory conditions for 7 days. After 20 days, there was a 37 percent fall in the glucose levels of the samples. Using sodium-fluoride treated filter papers, glucose values were stable for more than 30 days (Fig. 3).

COST COMPARISON: A cost comparison can only be approximate but may still be of interest. 


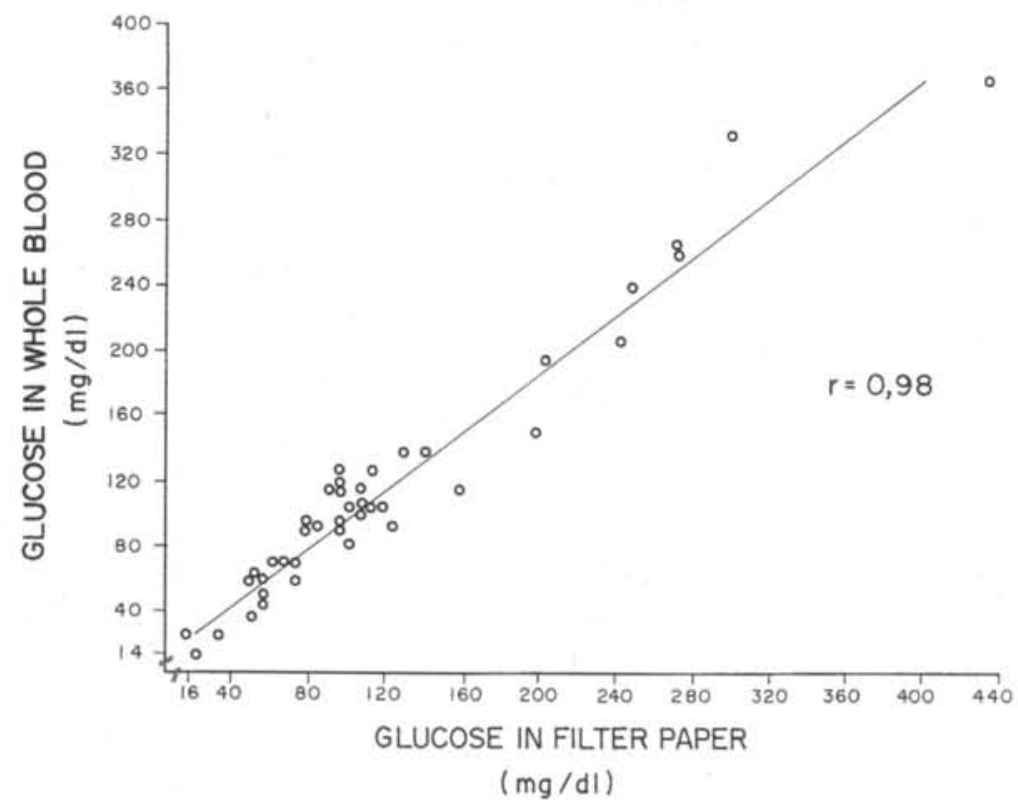

Figure 2 - Relationship between the filter paper glucose values and those determined in whole blood.

The filter paper method is cheap and simple, requiring only the paper and finger-pricking equipment. In contrast, home monitoring with glucose reagent strips involves acquisition and maintenance of a reflectomer and strips. In Brazil, most of the reagent strips are imported. The final cost of blood glucose determinations using filter paper is, therefore, approximately five times less than the determination with the reflectometers.

\section{DISCUSSION}

The method described is simple to use. The only aspect patients have to be concerned about is the appropriate size

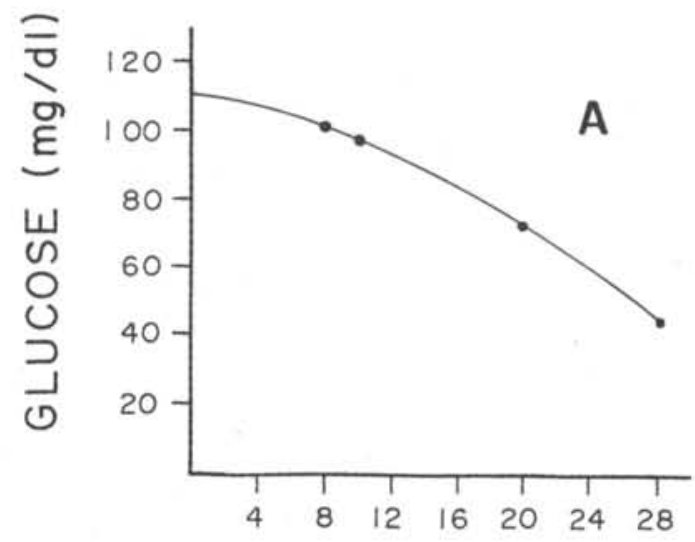

of the spots and that they become completely soaked with blood. Since diabetic patients are used to needles, the need for repeated fingerpricks is not a serious problem'. Like WAKELIN et al., we have obtained acceptable results following storage of the samples at room temperature ${ }^{10}$. In addition, the stability of glucose was found to be enhanced by pretreating the filter papers with a 2 percent solution of sodium fluoride. The sample stability and the simplicity of handling the filter paper are of practical importance as they permit samples to be collected over several days and to be sent to the laboratory by mail ${ }^{8}$.

In the above method, filter paper specially designed for sampling is used. In addition, an enzymatic procedure that is practically free from interference is employed. The method is definitely cheaper than the use of glucose strips and reflectance meters, and the results are more reliable since the final analysis is performed in a laboratory ${ }^{2}$.

The method is suitable for periodic determinations of blood glucose levels during everyday activity. It also useful for the intermittent assessment of diurnal blood glucose profiles, or the temporary assessment of particular problems. Since little equipment is needed and blood sampling takes little time, the method is also suited to various situations outside the patient's home. As pointed out by the DCCT, this is very important in diabetes care since there is a clear correlation between good glycemic control and a reduction in chronic diabetes complications such as retinopathy, neuropathy and nephropathy'.

The method described may also be useful in the diagnosis of postprandial hypoglycemia. Postprandial or reactive hypoglycemia poses a difficult diagnostic challenge

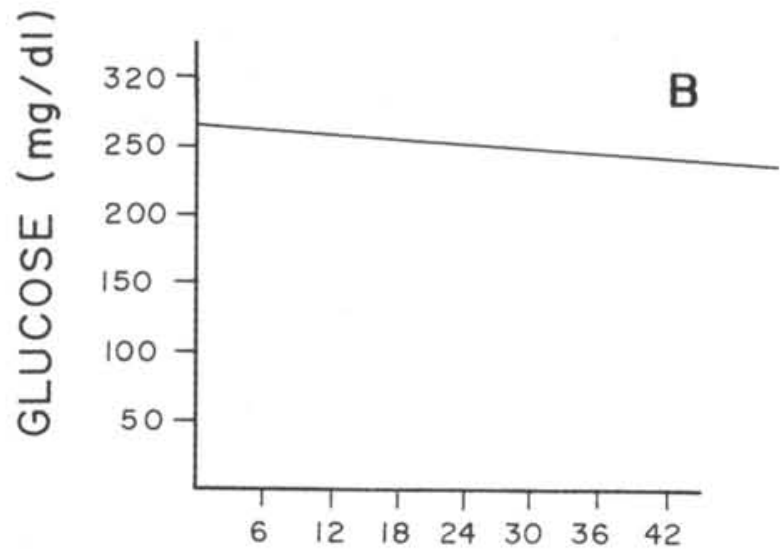

Figure 3 - Glucose concentration in the filter paper blood samples in the absence of inhibitors of (A) glycolysis and using sodium fluoride $(\mathrm{B})$. 
because the symptoms are nonspecific, the diagnosis is often made by the patients themselves, and there is no reliable diagnostic test. The evaluation of patients with postprandial symptoms suggestive of hypoglycemia requires the measurement of blood glucose at the time of spontaneously occuring symptoms and avoidance of the oral glucosetolerance test. The filter-paper method for the measurement of blood glucose when symptoms are present can therefore help to obtain a correct diagnosis. 12,13 .
The disadvantage for the patients of not getting the results immediately may be overcome by taking notes. Our experience is that the filter paper method is an aid to improved diabetes control.

In conclusion, we have described a method for the determination of blood glucose using dried filter paper blood spots. This method is a cheap alternative that may improve the control of diabetes mellitus, and may also be useful in the diagnosis of postprandial hypoglycemia.

\section{RESUMO}

Apresentamos um método de dosagem de glicemia em papel de filtro. Para comprovar seu valor, comparamos os resultados obtidos no papel de filtro e no sangue venoso colhidos simuitaneamente. Demonstramos que existe uma relação linear entre a glicemia dosada no papel de filtro e a do sangue periférico. Nāo houve diferença estatistica entre os doıs metodos ( $p>0,05$ ). O método se constitui em uma alternativa barata no controle do diabetes melittus e pode ser usado também no diagnóstico da hipogiicemia reativa e em outras situaçōes especiais.

\section{REFERENCES}

1. Äbyholm AS. Determination of glucose in dried filter paper blood spots. Scand J Clin Lab Invest 1981; 41:269-274.

2. Burrin JM, Price CP. Performance of three enzymic methods for filter paper glucose determination. Ann Clin Biochem 1984; 21:411-415.

3. Cryer PE. Glucose homeostasis and hypoglycemia. In: Wilson JD, Foster DW, eds. Williams Textbook of Endocrinology. 7th ed. Philadelphia:W.B. Saunders 1985: 989-1017.

4. DCCT Update - Symposium. $53^{\text {rd }}$ Meeting of the American Diabetes Association Las Vegas, U.S.A., 1993.

5. Hayes TM, Hayes E. Assessment of diabetic control: a comparison between home and clinic blood glucose levels. Diabetes Care 1978;1:166-171.

6. Hill JB, Palmer. Filter paper blood collection and punching as a means of quantification. Clin Chem $1969 ; 15: 381$.

7. Keen H, Knight RK. Self-sampling for blood glucose sugar. Lancet 1962:1037.

8. Knight RK, Keen H. Blood sugar by post. Br Med J 1961;1:1168.

9. Lefebvre PJ, Andreani D, Marks V, Creutzfeldt W. Statement on postprandial hypoglycemia. Diabetes Care 1988;11:439-440.
10. Lott JA, Turner K. Evaluation of Tinder's glucose oxidase method for measuring glucose in serum and urine. Clin Chem 1975;21:1754.

11. Malone JI, Rosebloom AL, Gric A, Weber FT. The role of urine sugar in diabetic management. Am J Dis Child 1976;130:1324-1330.

12. Palardy J, Havrankova J, Lepage R, Matte R, Bélanger R, d'Amour P, Ste-Marie LG. Blood glucose measurements during symptomatic episodes in patients with suspected postprandial hypoglycemia. NEJM 1989;321:1421.

13. Seltzer HS. Spontaneous and drug-induced hypoglycemia. In: Brodoff BN, Bleicher SJ, eds. Diabetes Mellitus and obesity. Baltimore: Williams \& Wilkins, 1982;414-436.

14. Sonksen PH, Judd SL, Lowry C. Home monitoring of blood glucose. Lancet 1979;1:729-735.

15. Tattersall RB. Home blood glucose monitoring. Diabetologia 1979;16:71-77.

16. von Schenck H, Arnqvist H, Jagenburg O. Reliability of blood glucose determined with the glucometer under laboratory and field conditions. Excerpta Med Int Congr Ser 1982; 577:207.

17. Wakelin K, Goldie DJ, Hartog M, Robinson AP. Measurement of capillary blood glucose in filter-paper spots: an aid to the assessment of diabetic control. Br Med J 1978:2:468. 